\title{
Justification of the parameters of the floating crop lifter when mowing crops
}

\author{
Kukhmaz Kukhmazov ${ }^{1}{ }^{*}$, Vladimir Konovalov ${ }^{2}$, and Andrey Malyshev ${ }^{1}$ \\ ${ }^{1}$ Penza State Agrarian University, 30 Botanicheskaya St., Penza, 440014, Russia, \\ ${ }^{2}$ Penza State Technological University, 1A/11, Baydukova passageway /Gagarina St., Penza, 440039, \\ Russia
}

\begin{abstract}
When harvesting dead plants the reapers and mowers are equipped with crop lifters, which lift and feed dead plants (stems) to the cutter. High-quality work of well-known crop lifters is not always ensured due to poor following the relief of the mowed area. Therefore, the aim of the study was to improve the design of a stem lifter of a mower or header and to justify its parameters experimentally. The floating crop lifter is proposed for the use. It consists of a runner pivotally attached to the base, and the base is attached to the finger bar of the header cutter. A lifting pen is rigidly fixed to the runner at an angle of $35^{\circ}$. Between the base of the runner and the lifting pen, a gas strut with excess pressure is installed. The manufactured laboratory unit made it possible to carry out experimental studies. Implementation of the experimental design and computer processing of the obtained results made it possible to justify the optimal values of a number of indicators of the design of the crop lifter. The smallest material losses (less than 1\%) were observed at coded values of the factors: $\mathrm{X} 1=0 \ldots 0.5 ; \mathrm{X} 2=-0.25 \ldots 0.25 ; \mathrm{X} 3=-0.5 \ldots 0$. This corresponded to the natural values of the studied factors: runner length $1=$ $450-500 \mathrm{~mm}$; the load of the gas strut $\mathrm{P}=45-55 \mathrm{~N}$; operating speed of the unit $v=1.2-1.6 \mathrm{~m} / \mathrm{s}$. The obtained exponential dependence on the parabolic function of these factors adequately describes the experimental results.
\end{abstract}

\section{Introduction}

Harvesting plants involves cutting them at the required height and removing the plant mass for subsequent disposal or processing. Either green mass is removed from the cultivated area (mowers and trimmers are used to cut plants) or ripened plants with seeds (ripened plants are cut by the reapers, and the resulting heap of straw with grain must be threshed and separated) $[1,2,3]$. In agriculture, in crop production the main produced product is the grain mass [4]. In this case, harvesting is complicated with dead plants and requires specialization of equipment for their preliminary rise and delivery for cutting [5]. Therefore, the development of such a machinery is aimed both at improving the design of devices $[6,7,8]$, and at increasing their efficiency $[9,10,11]$.

The imperfection of the design of technical devices leads to the loss of plant mass in all

${ }^{*}$ Corresponding author: konovalov-penza@rambler.ru 
areas of its processing. The position of the knife relative to the soil surface and the presence of supply devices have a significant effect on the cut height of the plant [12]. In this case, the vibrations of the header design elements have a significant value $[13,14]$. The task of raising plants for mowing them with following the surface of the soil is also relevant in fodder production and in public utilities.

To lift dead plants, headers or mowers are equipped with crop lifters. The patent RU 18066 [5] proposes the use of lifting pens with runners attached to the header body with plate springs. The disadvantage of this design is the fatigue and breakage of the metal springs during active operation of the header.

The aim of the research was to improve the design of the header crop lifter and experimental justification of its parameters.

\section{Methods and materials}

It is proposed to use a floating crop lifter, consisting of a runner 1 (Figure 1), pivotally attached to the base of the runner 2 . A lifting pen 3 is rigidly fixed to the runner 1 , and the angle between the runner line 1 and the surface of the lifting pen 3 is an angle $\alpha$. Between the base 2 and the lifting pen 3, a gas strut 4, consisting of a pressure cylinder and a rod with a piston package (pneumatic cylinder) is installed. Gas under pressure in the rodless cavity of the pressure cylinder of the gas strut 4 plays the role of an elastic element. The rod of the gas strut 4 is pivotally connected to the lifting pen 3, and the pressure stop cylinder of the gas strut 4 is connected to the base 2 . The floating crop lifters are attached to the finger bar of the header cutter.

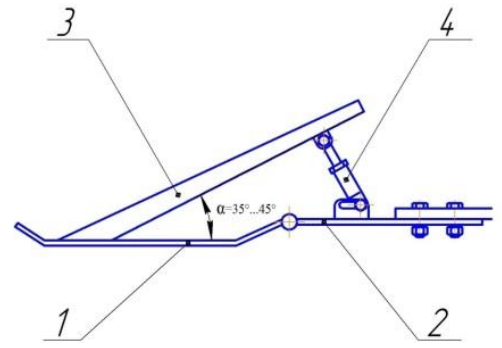

Fig. 1. The structural scheme of the crop lifter: 1 - runner; 2 - base of the runnere; 3 - lifting pen; 4 gas strut.

To justify the design and operating parameters of the floating crop lifter, we conducted experimental studies on a laboratory unit consisting of frames 1 and 2 (Figure 2), on which a feed belt conveyor 3 , a cutter 4 and a floating crop lifter 5 are installed. The belt conveyor 3 is mounted on the frame 1 , and the cutter 4 and the crop lifter 5 - on the frame 2 . The feed belt conveyor 3 is driven by a gear motor 6 through a chain transmission. The speed of the feed belt conveyor 3 is regulated by interchangeable sprockets. To the conveyor belt 3 are attached the stalks 7 of a grain crop with a given lodging. The cutter 4 is driven by an electric motor 8, with the help of a V-belt transmission 9 and a swinging block linkage 10 . To collect the cut stems, there is a box-collector 11 under the cutter.

The laboratory unit works as follows: first, on the feed belt conveyor 3, the stems 7 with a given lodging are fixed. On the frame 2 we install the tested floating crop lifters 5 . We select the required speed of the feed belt conveyor 3 . We sequentially turn on the drive of the cutting device 4 and the feed conveyor 3 . When the conveyor belt 3 moves, the dead stems are risen by the floating crop lifter 5 into the cutting area, cut off by the cutting device 4 and fall into a collection box 11 . Uncut stems 12 remain on the conveyor belt 3 .

The quality indicators of the floating crop lifter of the combing header depend on many factors. Therefore, laboratory studies were carried out using the methodology of planning a 
multivariate experiment.

The loss of grain crops $(\mathrm{G}, \%)$ in the form of the number of uncut stems was used as an optimization criterion:

$$
\mathrm{G}=\frac{\sum_{\mathrm{i}=1}^{100}\left(\mathrm{n}_{\mathrm{i}}-\mathrm{n}_{\mathrm{c}}\right)}{\mathrm{n}_{\mathrm{i}}} \cdot 100
$$

where $n_{i}-$ the number of fixed stems before the experiment, pcs.; $n_{c}-$ the number of cut stems after the experiment, pcs.
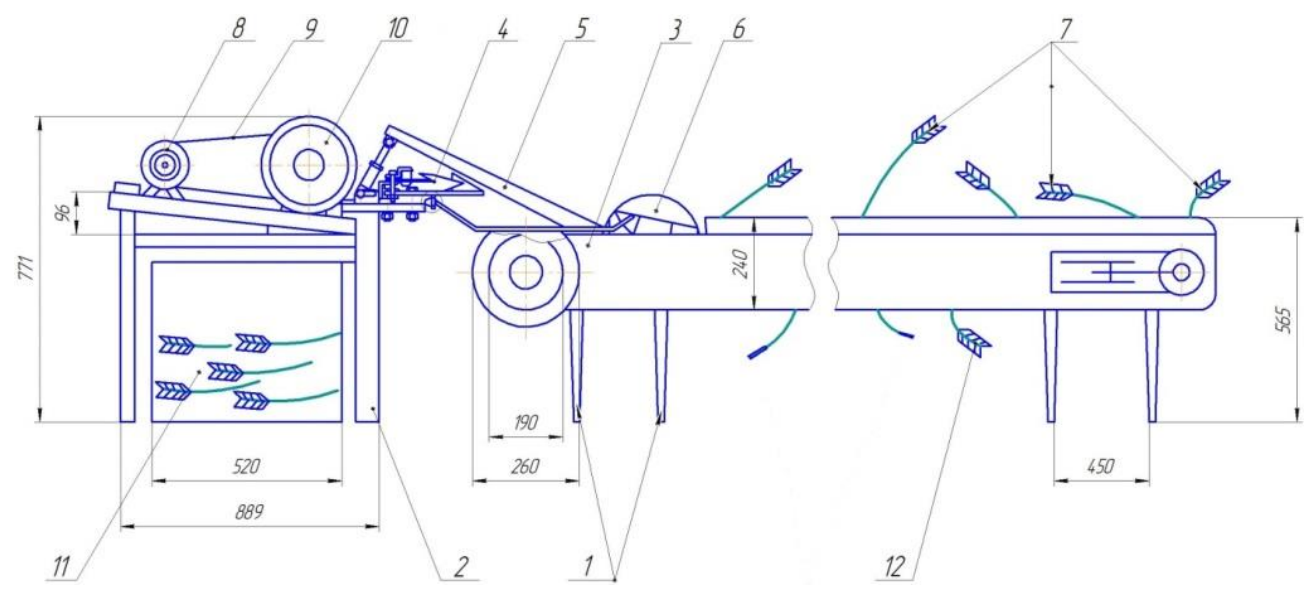

Fig. 2. The scheme of the laboratory unit to justify the parameters of the crop lifter: 1,2-frame; 3-feed conveyor; 4-cutter; 5-floating crop lifter; 6-gear motor drive; 7-stems; 8-electric motor; 9-V-belt transmission; 10-swinging block linkage; 11-box-collector; 12- uncut stems

Based on apriori information from the results of studies on the state of sowing crops during the harvesting period, as well as on the basis of specific research tasks, the most significant factors affecting the loss of crops during harvesting with a combing header were identified. During the study, some of them did not change and were fixed at constant levels.

The most significant factors include: length of a runner $l, \mathrm{~mm}$; load value of gas strut $P$, $\mathrm{N}$; working speed $v, \mathrm{~m} / \mathrm{s}$. Accordingly, these factors were designated as encoded factors $\mathrm{X} 1, \mathrm{X} 2, \mathrm{X} 3$. The minimum, average, and maximum natural values of these factors corresponding to the coded values $(-1.0 ; 0.0 ;+1.0): l=(350 ; 450 ; 550 \mathrm{~mm}), P=(30 ; 50 ; 70$ $\mathrm{N}), v=(0.8 ; 1.6 ; 2.4 \mathrm{~m} / \mathrm{s})$.

\section{The results of the studies}

As a result of approximating the obtained empirical average values over three repetitions of measurements of the experimental results, the parabolic regression equation was established:

$$
\begin{aligned}
Y= & -1.33-1.64 \cdot X_{1}-1.66 \cdot X_{2}+3.18 \cdot X_{3}+3.41 \cdot X_{1}^{2}+6.71 \cdot X_{2}^{2}+ \\
& +4 \cdot X_{3}^{2}+0.36 \cdot X_{1} \cdot X_{2}+0.29 \cdot X_{1} \cdot X_{3}+0.99 \cdot X_{2} \cdot X_{3}
\end{aligned}
$$

The value of the Pearson coefficient $\mathrm{R}=0.96279$ indicates a good correlation of the calculated and experimental values. However, the value of F-test $=0.889163$ indicates a confidence probability of the model of less than $90 \%$, which indicates the inadequacy of the obtained model. Given the presence of negative calculated values of losses according to the model (the lower left corner of the graph, Figure 3), which is physically impossible, the application of the obtained regression equation is limited, especially for small values of 
losses.

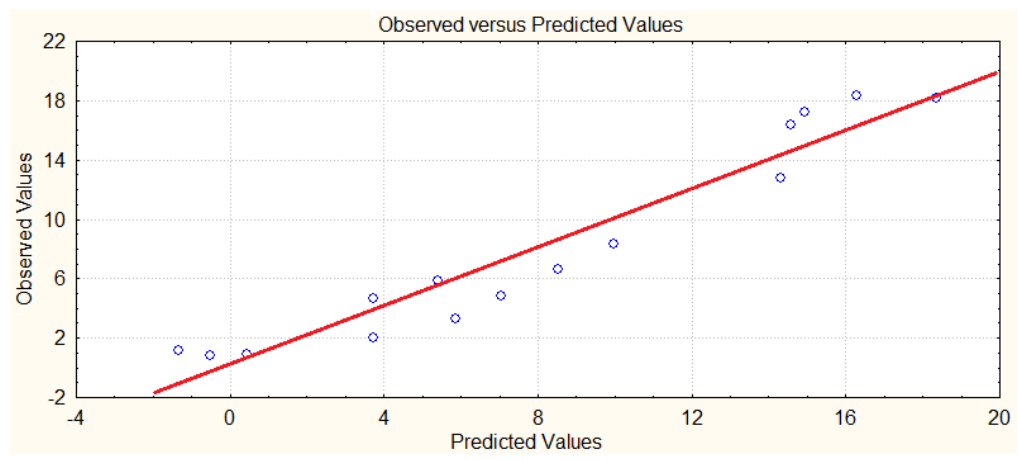

Fig. 3. The similarity of the calculated values of the result and the experimental data

Taking into account that the description of the process in the zone of minimal losses is the main task of the resulting model, we were forced to abandon it, moving on to more complex models. For the refined model, the measurement results were subjected to natural logarithm. After this, as a result of approximation, a regression equation of the type was obtained:

$$
\begin{aligned}
& Y=\exp \left(a 0+a 1 \cdot X_{1}+a 2 \cdot X_{2}+a 3 \cdot X_{3}+a 11 \cdot X_{1}^{2}+a 22 \cdot X_{2}^{2}+\cdots\right. \\
& \left.+a 33 \cdot X_{3}^{2}+a 12 \cdot X_{1} \cdot X_{2}+a 13 \cdot X_{1} \cdot X_{3}+a 23 \cdot X_{2} \cdot X_{3}\right)
\end{aligned}
$$

Or after substituting empirical coefficients:

$$
\begin{gathered}
Y=\exp \left(0.0047-0.2 \cdot X_{1}-0.156 \cdot X_{2}+0.4 \cdot X_{3}+0.334 \cdot X_{1}^{2}+\cdots\right. \\
\left.+1.6 \cdot X_{2}^{2}+0.525 \cdot X_{3}^{2}+1.6 \cdot X_{1} \cdot X_{2}+0.05 \cdot X_{1} \cdot X_{3}+0.12 \cdot X_{2} \cdot X_{3}\right)
\end{gathered}
$$

Judging by the numerical values of the coefficients before the factors, the most significant were: the square of X2 $(+1.6)$, the pair influence of X1 and X2 $(+1.6)$, the square of X3 $(+0.525)$ and X3 $(+0.4)$. All these factors were positive, which indicated an increase in the value of the losses with their increase (at least, more than a certain value). Taking into account the second degree of factors, this indicated the possible presence of an extremum.

The amount of difference of unaccounted residuals by the regression model relative to zero (Figure 4) shows a good convergence of the results of the model and the experiment. The fact that unaccounted residuals are placed near the red line indicates a high confidence probability of the result. Points placed along a certain curve indicates the possibility of introducing an additional factor into the regression equation. However, the values of F-test $=0.953944$ allow using the obtained model with a confidence probability of $95 \%$. This indicates the adequacy of the resulting model. The Pearson coefficient $\mathrm{R}=0.98441$ indicates a high correlation of the results. This is also evidenced by the convergence of the logarithms of the calculated values of the result and the experimental data (Figure 5).

Two-dimensional cross sections of factors $\mathrm{X} 1$ and $\mathrm{X} 2$ for $\mathrm{X} 3$ values equal to $(-1 ;-0.5$; $0 ; 0.5 ; 1)$ are presented in Figure 6 . The smallest losses (less than $1 \%$ ) are observed at X3 = $-0.5 \ldots 0$, as well as at the values of $\mathrm{X} 1$ about $0 \ldots 0.5$ and $\mathrm{X} 2$ about $-0.25 \ldots 0.25$. 


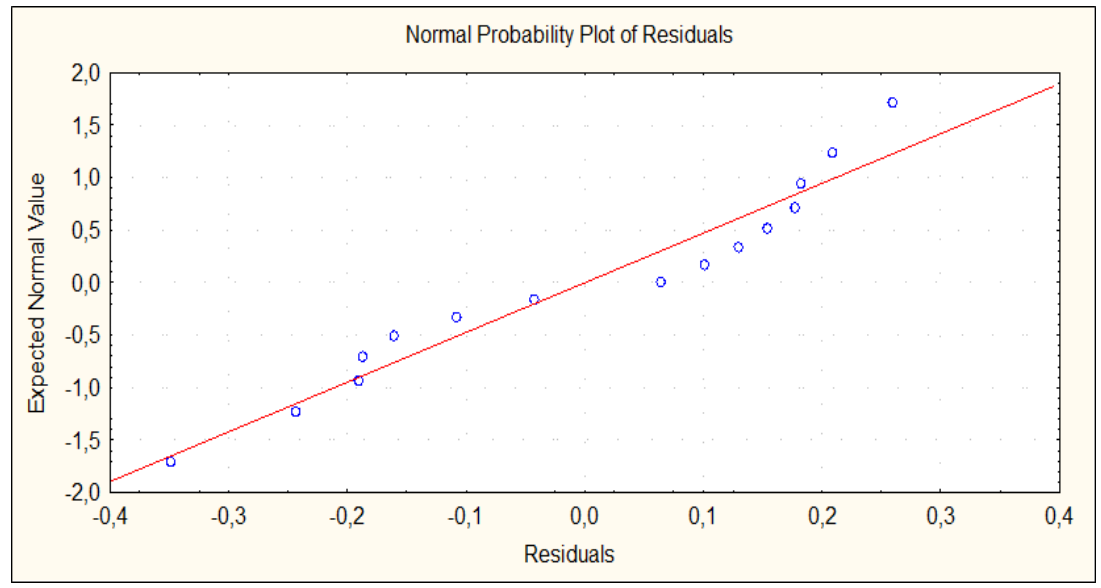

Fig.4. Placement of unaccounted residuals by the model relative to the normal distribution line

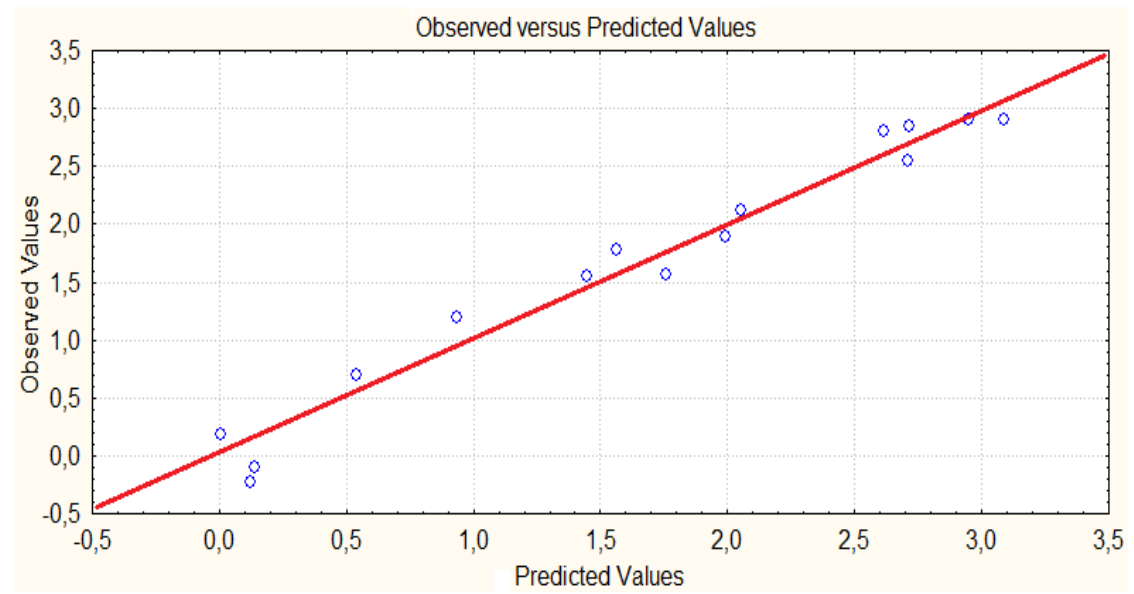

Fig.5. Convergence of the logarithms of the calculated values of the result and the experimental data

\section{Conclusion}

Rising plants for subsequent cutting of their stems is provided by a floating crop lifter, consisting of a runner pivotally attached to the base, and the base is attached to the finger bar of the header cutter. A lifting pen is rigidly fixed to the runner at an angle of $35^{\circ}$. Between the base of the runner and the lifting pen, a gas strut with excess pressure is installed. The manufactured laboratory unit made it possible to carry out experimental studies. The implementation of the experimental design and computer processing of the obtained results made it possible to substantiate the optimal values of a number of indicators of the design of the crop lifter. The smallest material losses (less than 1\%) were observed at coded values of factors: $\mathrm{X} 1=0 \ldots 0.5 ; \mathrm{X} 2=-0.25 \ldots 0.25 ; \mathrm{X} 3=-0.5 \ldots 0$. This corresponded to the natural values of the studied factors: runner length $l=450-500 \mathrm{~mm}$; the load of the gas strut $P=45-55 \mathrm{~N}$; the operating speed of the unit $v=1.2-1.6 \mathrm{~m} / \mathrm{s}$. The obtained exponential dependence on the parabolic function of these factors adequately described the experimental results. 


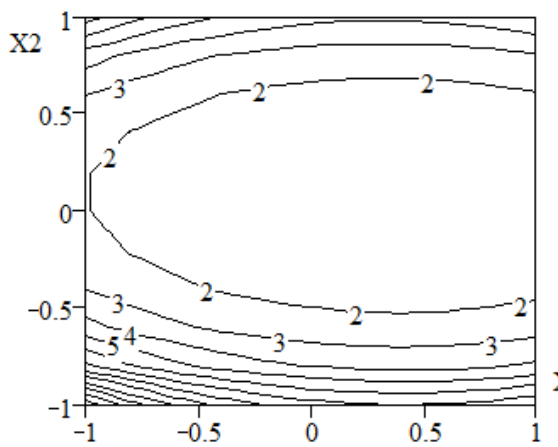

$\mathrm{Y}_{\tau 1}$

(a)

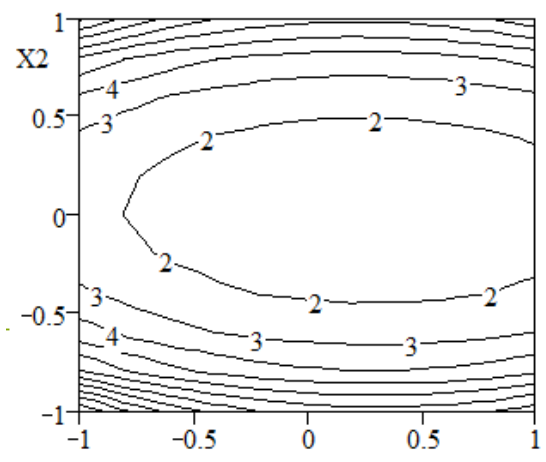

$\mathrm{Y}_{05}$

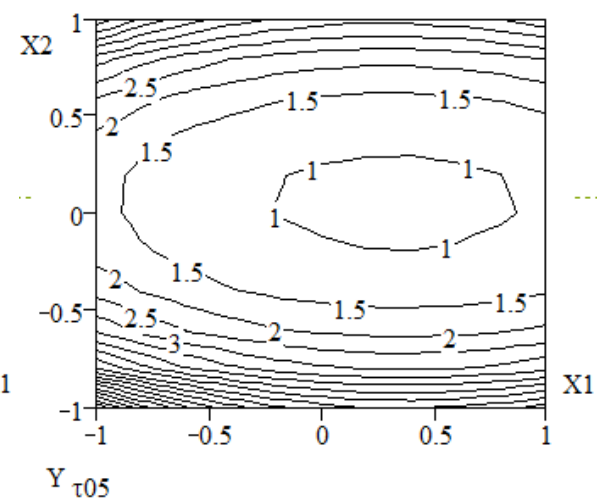

(b)

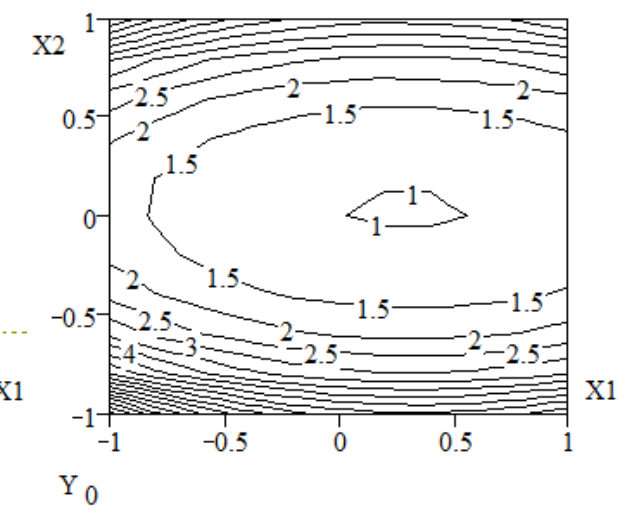

(d)

(c)

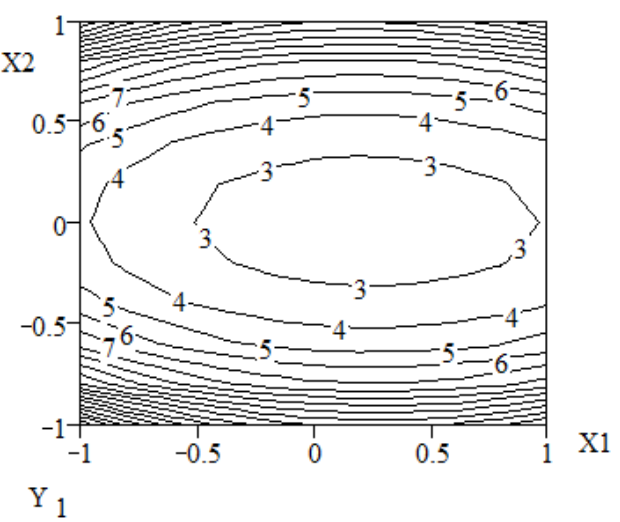

(e)

Fig. 6. The influence of factors $\mathrm{X} 1$ and $\mathrm{X} 2$ on the percentage loss of product $\mathrm{Y}$ with $\mathrm{X} 3$ values equal, respectively: (a) --1.0 ; (b) --0.5 ; (c) -0.0 ; (d) -+0.5 ; (e) -+1.0 


\section{References}

1. Q. Liao, Y. Xu, J. Yuan, X. Wan, Y. Jiang, Transactions of the Chinese Society for Agricultural Machinery, 50(7) 140-150 (2019)

2. M. Konstantinov, I. Gluchkov, I. Ognev E3S Web of Conferences 12600046 (2019) DOI https://doi.org/10.1051/e3sconf/201912600046

3. H. Liu, A.R. Reibman, A.C. Ault, J.V. Krogmeier Proceedings - 2nd International Conference on Multimedia Information Processing and Retrieval, MIPR 20198695327 310-315 (2019). DOI: 10.1109/MIPR.2019.00062

4. Patent for utility model RU 180 669. Application: 2018102787, 24.01.2018. Application submission date: 24.01.2018. Published: 21.06.2018 Bulletin No. 18, p.5. Tizov V.M., Kukhmazov K.Z. Patent holder - "Penza State Agrarian University"

5. E. Zareishahamat, S.A. Pour, M. Maysami, Agricultural Engineering International: CIGR Journal 21(3) 104-113 (2019).

6. J. Pang, Y. Li, J. Ji, L. Xu, Biosystems Engineering 185, 25-34 (2019)

7. H. Wang, H. Shen, S. Cao, (...), T. Han, H. Guo IOP Conference Series: Earth and Environmental Science 233(3), 032012 (2019).

8. Z. Guan, C. Wu, G. Wang, H. Li, S. Mu, Transactions of the Chinese Society of Agricultural Engineering 35(3), 1-8. (2019)

9. V. Bulgakov, V. Adamchuk, S. Ivanovs, H. Kaletnik, Engineering for Rural Development 18, 256-263 (2019). DOI: 10.22616/ERDev2019.18.N387

10. A. Md. Rostom, H. Md. Kamrul, C.K. Saha, A.Md. Monjurul, 2019 ASABE Annual International Meeting. (2019) DOI: 10.13031/aim.201900727

11. V.Bulgakov, V. Nadykto, S. Ivanovs, J. Nowak, Engineering for Rural Development 18, 136-143 (2019). DOI: 10.22616/ERDev2019.18.N169

12. A.A.Almosawi, Plant Archives 19, 203-207 (2019).

13. Z. Tang, H. Zhang, Y. Zhou, Y. Li , Advances in Materials Science and Engineering 2019, $\mathbf{6 8 3 4 2 6 9}$ (2019). https://doi.org/10.1155/2019/6834269

14. G. Kozlov, M. Pushkarev, E3S Web of Conferences 135, 01058 (2019). DOI: $10.1051 / \mathrm{e} 3$ sconf $/ 201913501058$ 